九州大学学術情報リポジトリ

Kyushu University Institutional Repository

\title{
A High Gain Dual Band Microstrip Patch Antenna Design Implementing Rectangular Slotted Electromagnetic Band Gap Structure
}

Das, Urmi

Chittagong University of Engineering and Technology (CUET)

Jahan, Nusrat

Chittagong University of Engineering and Technology (CUET)

https://doi.org/10.5109/4102464

出版情報: Proceedings of International Exchange and Innovation Conference on Engineering \& Sciences (IEICES). 6, pp.60-66, 2020-10-22. Interdisciplinary Graduate School of Engineering Sciences, Kyushu University バージョン：

権利関係 : 


\title{
A High Gain Dual Band Microstrip Patch Antenna Design Implementing Rectangular Slotted Electromagnetic Band Gap Structure
}

\author{
Urmi Das*, Nusrat Jahan \\ Chittagong University of Engineering and Technology (CUET), Chittagong, Bangladesh \\ *Corresponding author email: urmidas630@gmail.com)
}

\begin{abstract}
In this work, a dual band microstrip patch antenna has been designed by employing Electromagnetic Band Gap (EBG) structure. The antenna bandwidth and gain have been improved by incorporating four rectangular slots and one U-shaped slot in each EBG cell. Without the slot, the microstrip patch antenna only radiates at nearly $3 G H z$. The gap effect between the EBG unit cells and via diameter effect of electromagnetic band gap structure has also been analyzed for microstrip patch antenna. Our proposed antenna achieves a gain of $2.42 \mathrm{~dB}$ and $2.64 \mathrm{~dB}$ at $3.09 \mathrm{GHz}$ and $5.44 \mathrm{GHz}$ in the S-band and C-band respectively. The comparison between proposed EBG structure and mushroom type $E B G$ structure has been investigated. The impedance bandwidth is extended by $3.24 \%$ and $5.33 \%$ at $3.09 \mathrm{GHz}$ and $5.44 G H z$, respectively.
\end{abstract}

Keywords: Mushroom-like Electromagnetic Band Gap; Microstrip Patch Antenna; Dual Band.

\section{INTRODUCTION}

With the increasing demand of high-data rate, high-gain antennas become an integral part of modern wireless and telecommunication systems. In antenna design, surface waves produce leakage losses, which reduce antenna gain, bandwidth and efficiency due to the enhancement of large side and back radiation. Surface waves propagate inside the substrate of antennas and stays confined within the substrate when the dielectric constant $\left(\epsilon_{r}\right)$ of substrate is more than one. Surface waves also produce problem in antenna array design by increasing mutual coupling. To solve the problem of surface wave propagation in antenna design, different electromagnetic band-gap (EBG) structures have been immensely used to improve the antenna performances. In recent years there has been a tremendous research on investigating electromagnetic band gap (EBG) structures. Electromagnetic band gap (EBG) is a periodic structure of metal patches with connected vias to ground on dielectric substrates [1]. The shorted via between the metal patch and ground plane is contributing to form inductance while capacitance is realized by the gap between the electromagnetic band gap (EBG) unit cells. Electromagnetic band gap (EBG) structure works like a stop band to oppose surface waves of certain frequency bands.

A novel Electromagnetic band gap (EBG) structure has been proposed by cutting two I-shaped slots into the patch of a mushroom-type EBG structure and studied the performance of a low profile antenna over the EBG structure [2]. To reduce the effect of the surface wave problem, various EBG structures have been proposed by several researchers which provide various advantages. A circularly polarized microstrip antenna with dual feed and a cross slot has been presented by employing electromagnetic band gap (EBG) structure [3]. Omnidirectional microstrip antenna with $6 \times 6$ array of EBG unit cell has been proposed for the short range and medium range wireless network operation[4]. In [5], a novel dual band gap two via double slot loaded electromagnetic band gap (TVDS-EBG) structure has been analyzed for ultra wide band monopole antenna to achieve dual notch. Here, two resonance circuit per unit cell results in dual band gap in X-and Y-direction. In [6], a novel dual band electromagnetic band gap (EBG) structure has been designed for microstrip antenna with a U-shaped slot. Here, dual band gap EBG structure consists of an internal small patch, an external ring patch and two metallic vias, which is used to minimize mutual coupling between the microstrip antennas. In [7], a dual band spiral slot microstrip antenna has been designed by incorporating pin-wheel shaped electromagnetic band gap (EBG) structures. Spiral slots have been incorporated in patch antenna to achieve dual band gap. In [8], a rectangular patch antenna has been designed, surrounded by mushroom EBG patch and analyzed the results for different number of EBG column. Due to increasing number of EBG column, the performance of patch antenna has been increased. In [9], multiple band gap structures like mushroom EBG, partial substrate removal and grid EBG have been designed and analyzed for their band gap properties. A circularly polarized (CP) microstrip patch antenna [10] has been designed for GPS application. Here, right hand circular polarization has been produced by cutting two corners of the patch and miniaturizing physical dimension of the antenna has been done by using electromagnetic band gap underneath of the antenna. A new electromagnetic band gap (EBG) structure using fractal geometry has been designed and analyzed its effect on Hexagonal Patch antenna performance [11]. A novel dual-band compact rabbet spiral electromagnetic (EBG) structure [12] consisting of two different lattice units: concave patch and convex patch with inserted spiral branches has been designed. The windings of spiral branches and metal size of patches were kept different to form different inductances and capacitances to achieve dual frequency band. In [13], a dual band slotted Electromagnetic band gap structure has been designed to achieve wide bandwidth and analyzed its characteristics for monopole antenna. 
In this work, we propose a microstrip patch antenna implementing slotted EBG structure for dual band application. The introduction of rectangular and Ushaped slots in EBG unit cell results in an improved antenna gain with a higher bandwidth.

\section{PROPOSED ANTENNA DESIGN}

In this work, a novel dual band gap electromagnetic band gap (EBG) structure has been proposed and analyzed the characteristics of microstrip patch antenna for this EBG structure. Electromagnetic band gap structure is the periodic structure of square metal patches which is designed to block the surface waves. The microstrip patch antenna can provide dual and triple frequency band with linear as well as circular polarization also. In recent years it became very popular because of some good features such as low weight, good performance characteristics, simple design and low fabrication cost [14]. It was found that to improve the bandwidth of the microstrip patch antenna, the use of single layer EBG substrates was not helpful [15]. For this reason here we use double layer substrates which may increase the bandwidth of microstrip patch antenna. To form double layer substrate, we placed another substrate layer of same dielectric constant and height above the EBG metallic patch layer. The square microstrip patch antenna has been employed above the double substrate layers. The substrate is made up of FR4 (lossy) material with a given dielectric constant $\left(\epsilon_{r}\right)$ and loss tangent $(\delta)$. The thickness of substrate is $h=1.6 \mathrm{~mm}$. The proposed antenna has a dimension of $47 \times 47 \mathrm{~mm}^{2}$. For excitation, we use $50 \mathrm{ohm}$ microstrip feeding line. The square patch, EBG patches and ground plane are made up of copper. The top view of the microstrip patch antenna is shown in Fig. 1(a). The side view of the antenna without EBG and with EBG is shown in Fig.1 (b) and 1(c), respectively. The dimensions of parameters of the proposed microstrip patch antenna are listed in Table I. The microstrip patch antenna which has length (L)and width (W) can be calculated by using (1)[16].

$$
\begin{gathered}
W=\frac{c}{2 f_{0}} \sqrt{\frac{2}{\epsilon_{r}+1}} \\
L_{e f f}=\frac{c}{2 f_{0 \sqrt{\epsilon_{\text {reff }}}}} \\
\epsilon_{\text {reff }}=\frac{\epsilon_{r}+1}{2}+\frac{\epsilon_{r}-1}{2}\left[1+12 \frac{h}{w}\right]^{-1 / 2} \\
\Delta L=0.412 h \frac{\left(\epsilon_{\text {reff }}+0.3\right)\left(\frac{W}{h}+0.264\right)}{\left(\epsilon_{\text {reff }}-0.258\right)\left(\frac{W}{h}+0.8\right)} \\
L=L_{\text {eff }}-2 \Delta L
\end{gathered}
$$

Where,

$C$ is light velocity, $W$ is the width of patch, $\epsilon_{r}$ is relative permittivity of the substrate, $\in_{\text {reff }}$ is effective relative permittivity of the substrate, $L_{\text {eff }}$ is effective length, $\Delta L$ is length extension, and $L$ is actual length of patch.

In recent years various types of EBG structures have been designed and analyzed their performances. In this

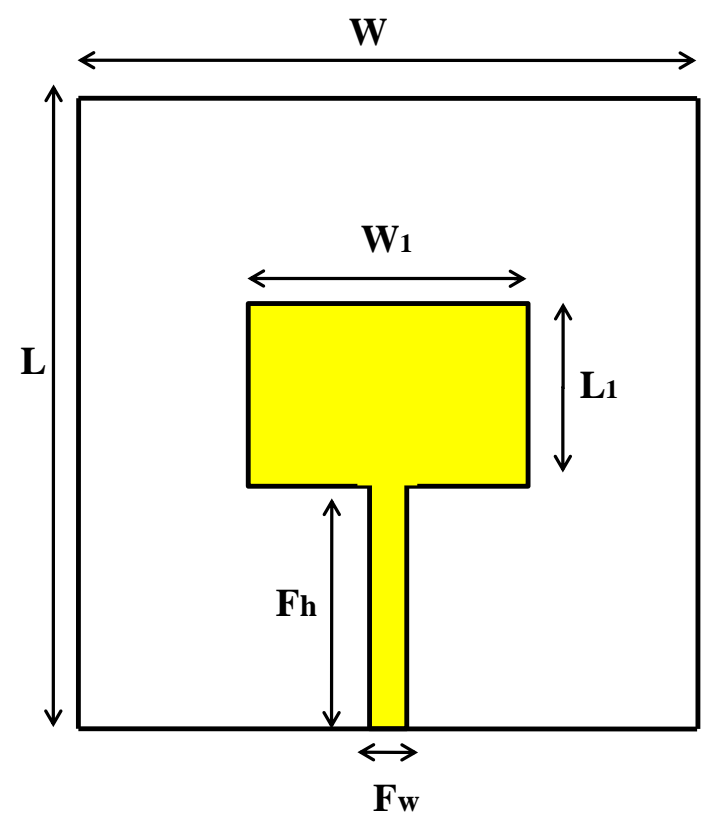

(a)

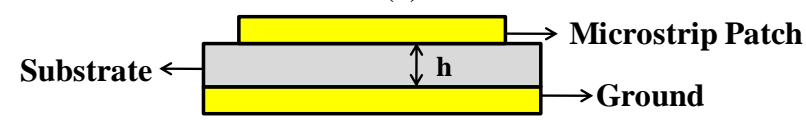

(b)

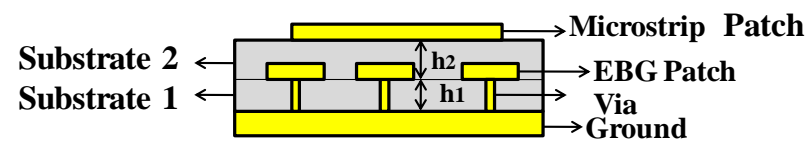

(c)

Fig.1. Proposed microstrip patch antenna (a) Top view (b) Side view without EBG (c) Side view with EBG.

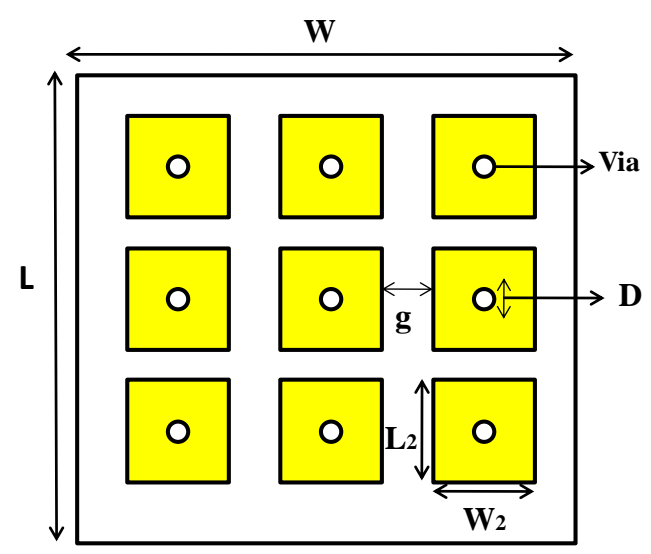

(a)

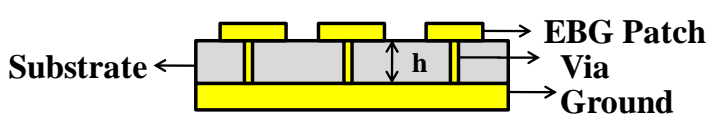

(b)

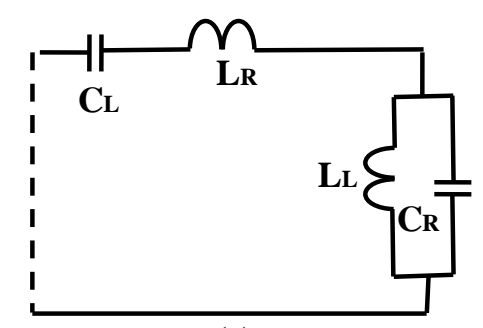

(c)

Fig.2. Mushroom-like EBG structure (a) Top view (b) Side view (c) Equivalent circuit of mushroom-like EBG unit cell. 
Table I. Optimized parameters of the proposed microstrip patch antenna

\begin{tabular}{cc}
\hline \hline Parameter & Value(mm) \\
\hline $\boldsymbol{h}$ & 1.6 \\
$\boldsymbol{h}_{\boldsymbol{1}}$ & 1.6 \\
$\boldsymbol{h}_{\boldsymbol{2}}$ & 1.6 \\
$\boldsymbol{\varepsilon} \boldsymbol{r}$ & 4.3 \\
$\boldsymbol{\delta}$ & 0.025 \\
$\boldsymbol{L}$ & 47 \\
$\boldsymbol{W}$ & 47 \\
$\boldsymbol{L}_{\boldsymbol{1}}$ & 23 \\
$\boldsymbol{W}_{\boldsymbol{l}}$ & 23 \\
$\boldsymbol{F}_{\boldsymbol{h}}$ & 12 \\
$\boldsymbol{F}_{\boldsymbol{w}}$ & 2 \\
\hline \hline
\end{tabular}

paper, we investigated and compared our proposed antenna performances using two types of EBG structure.

\section{(a) Mushroom-like Electromagnetic Band Gap structure (MEBG)}

The mushroom-like EBG structure consists of four parts: (a) dielectric substrate, (b) bottom ground plane, (c) square metal patches and (d) connecting vias. The mushroom-like EBG develops a stop band which inhibits the propagation of surface waves [17]. The geometric structure of $3 \times 3$ mushroom-like EBG and side view of this structure is shown in Fig.2 (a) and 2(b), respectively. The equivalent circuit of the mushroom EBG unit cell is shown in Fig. 2(c). The shunt inductance $\left(L_{L}\right)$ is formed by the shorted via between the patch and ground plane. The shunt capacitor $\left(C_{R}\right)$ is due to the capacitive coupling between the patch and ground plane. The series inductance $L_{R}$ is developed by the metal patch and $C_{L}$ is realized for gap capacitance between EBG unit cells. The dimensions of parameters of the mushroom-like EBG unit cell are listed in Table II. For a mushroom type EBG, the surface impedance $\left(Z_{s}\right)$, capacitance $(C)$, inductance $(L)$, resonance frequency $\left(f_{c}\right)$, and bandwidth $(B W)$ can be calculated by following equations[18].

$$
\begin{gathered}
Z_{S}=\frac{j \omega L}{1-\omega^{2} L C} \\
C=\frac{w \epsilon_{0}\left(1+\epsilon_{r}\right)}{\pi} \cosh ^{-1}\left(\frac{2 w+g}{g}\right) \\
L=\mu_{0} h \\
f_{c}=\frac{1}{2 \pi \sqrt{L C}} \\
B W=\frac{1}{\eta} \sqrt{\frac{L}{C}}
\end{gathered}
$$

Where, $\epsilon_{0}$ is permittivity of free space, $g$ is gap between unit elements in EBG structure, $\mu_{0}$ is permeability in free space, $h$ is thickness of the substrate, $w$ is patch width of the EBG structure, and $\eta$ is free space impedance.

The calculated value of capacitance and inductance are $C=0.6466 \mathrm{pF}$

$L=2.01 \mathrm{nH}$

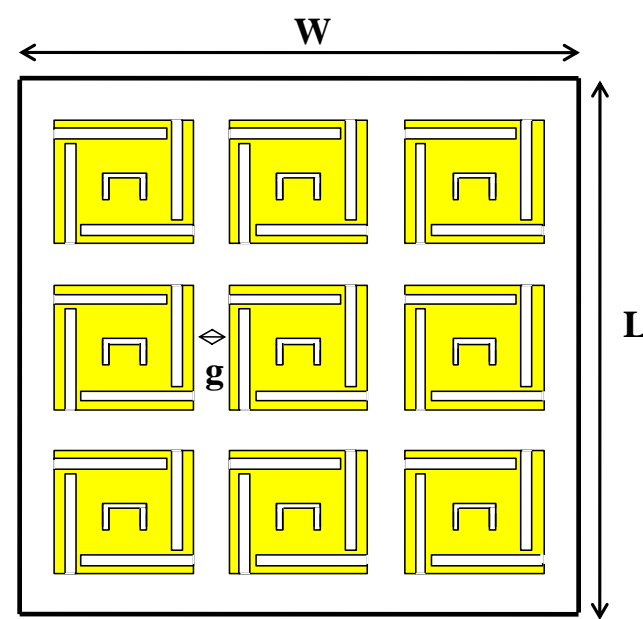

(a)
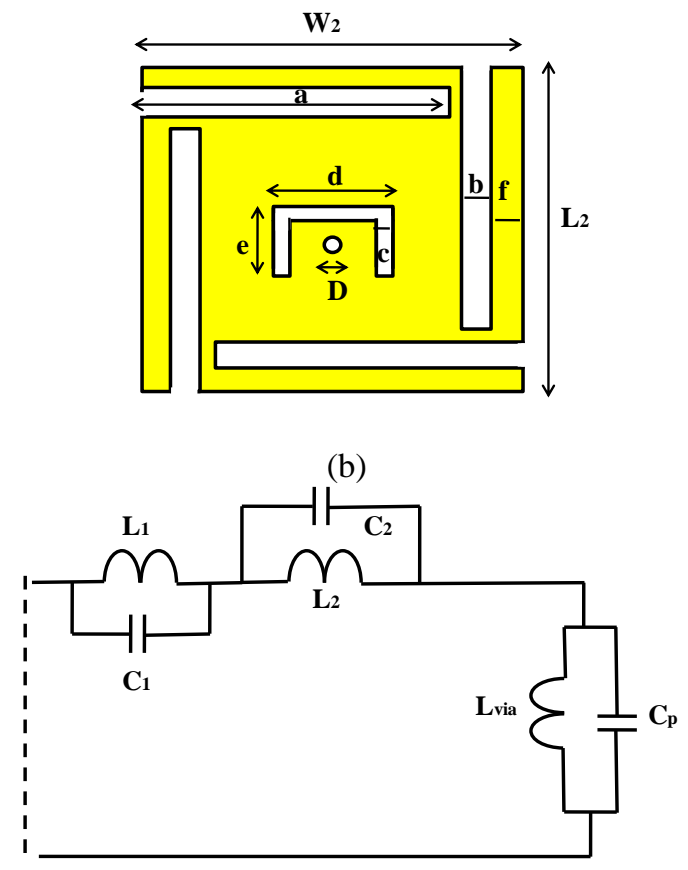

(c)

Fig.3. Geometries of slotted EBG structure (a) Top View (b) EBG unit cell (c) Equivalent circuit of the proposed EBG unit cell.

Table II. Optimized dimension of the mushroomlike EBG unit cell

\begin{tabular}{cc}
\hline \hline Parameter & Value $(\mathbf{m m})$ \\
\hline $\boldsymbol{W}_{\mathbf{2}}$ & 13 \\
$\boldsymbol{L}_{\mathbf{2}}$ & 13 \\
$\boldsymbol{D}$ & 0.8 \\
$\boldsymbol{g}$ & 2 \\
\hline \hline
\end{tabular}

Table III. Optimized dimension of the proposed slotted EBG unit cell

\begin{tabular}{cc}
\hline \hline Parameter & Value $(\mathbf{m m})$ \\
\hline $\boldsymbol{W}_{2}$ & 13 \\
$\boldsymbol{L}_{2}$ & 13 \\
$\boldsymbol{D}$ & 0.8 \\
$\boldsymbol{g}$ & 2 \\
$\boldsymbol{a}$ & 10.5 \\
$\boldsymbol{b}$ & 1 \\
$\boldsymbol{c}$ & 0.5 \\
$\boldsymbol{d}$ & 4 \\
$\boldsymbol{e}$ & 3 \\
$\boldsymbol{f}$ & 1 \\
\hline \hline
\end{tabular}


(b) Slotted Patch Electromagnetic Band Gap structure (SPEBG)

The second types of EBG structure that has been analyzed is a slotted patch electromagnetic band gap (SPEBG) structure. This newly designed EBG structure consists of four rectangular-shaped slots of $1 \mathrm{~mm}$ width and one U-shaped slot of $0.5 \mathrm{~mm}$ width. The rectangular and U-shaped slots are introduced in the square mushroom-like EBG structure to form more inductances and capacitances which will stop the propagation of electromagnetic waves. This new EBG structure can provide wider bandwidth with a second stop band frequency at higher frequency ranges compared to mushroom like EBG structure which only provides one stop band frequency at lower frequency ranges. Fig. 3(a). shows the geometric structure of $3 \times 3$ slotted EBG that has been modified through MEBG structure. The slotted EBG unit cell and equivalent circuit of the unit cell is shown in Fig. 3(b). and 3(c). The series inductance $L_{1}$ is formed by the internal patch and the interconnected rectangular four strips are contributing to the other series inductance $L_{2}$. Coupling capacitor $C_{1}$ is realized by the capacitive coupling between the patch and middle Ushaped slot while four rectangular slots are contributing to the other coupling capacitor $C_{2}$. The shunt inductance $\left(L_{v i a}\right)$ is developed by the shorted via between the patch and ground plane. The shunt capacitor $\left(C_{p}\right)$ is due to the capacitive coupling between the patch and ground plane. The dimensions of parameters of the proposed slotted EBG structure are listed in Table III. Equivalent circuit parameters for slotted EBG unit cell have been calculated by using equation (7) [20].

$$
\begin{gathered}
L_{1}=\mu_{0} h \\
L_{2}=2 \times 10^{-4} l\left[\ln \left(\frac{2 l}{W+H}\right)+o .5+\right. \\
\left.0.2235\left(\frac{W+H}{l}\right)\right] \\
C_{1}=C_{2}=\frac{\epsilon_{0} \epsilon_{r} A}{d} \\
L_{v i a}=K_{1} h\left[\ln \left(\frac{2 h}{r}\right)+1\right] \\
C_{p}=\frac{\epsilon_{0} \in_{r} w^{2}}{h} \\
C_{g}=\frac{w \epsilon_{0}\left(1+\epsilon_{r}\right)}{\pi} \cosh ^{-1}\left(\frac{w+g}{g}\right)
\end{gathered}
$$

Where, $C_{g}$ is gap capacitance between EBG unit cells, $h$ is the thickness of the substrate, $l$ is length of the strip, $W$ is the width of the strip, $H$ is the thickness of the strip, $A$ is area of plates, $d$ is the distance between plates, $w$ is the patch width of the slotted EBG unit cell, $g$ is the gap between unit elements in EBG structure, $r$ is via radius, and $K_{1}=0.2 \mathrm{nH} / \mathrm{mm}$.

\section{SIMULATED RESULTS}

The proposed antenna design is simulated and analyzed using Computer Simulation Technology (CST) Studio. The band gap frequency of electromagnetic band gap (EBG) structure can be determined by varying the metal patch width, gap between EBG unit cells and via diameter. To find resonance frequency with a wider bandwidth, the gap effect between EBG unit cells and via diameter effect has been analyzed. The gap between EBG
S-Parameter [Magnitude in dB]

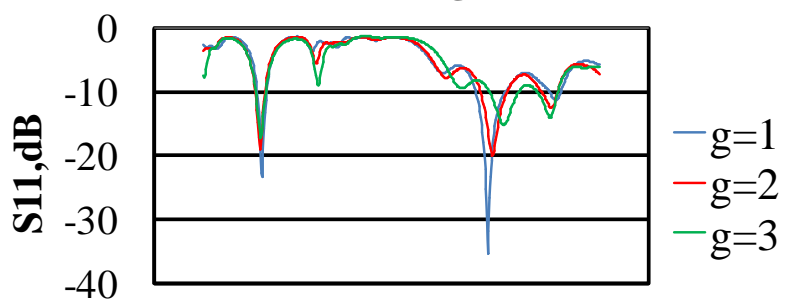

22.533 .544 .555 .566 .57

Frequency, GHz

Fig.4.Gap width effect of slotted EBG structure (via diameter, $\mathrm{D}=0.8 \mathrm{~mm}$ ).

\section{S-Parameter [Magnitude in $\mathbf{~ d B}$ ]}

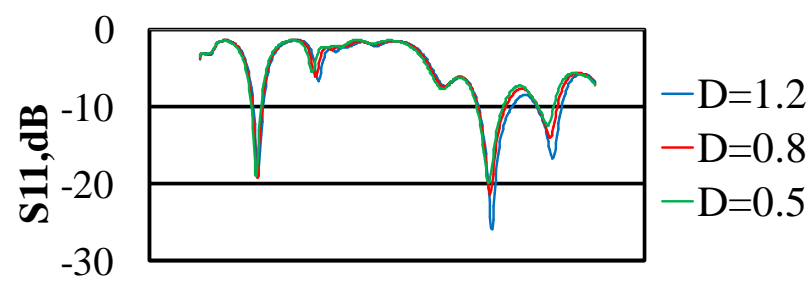

\subsection{3 .544 .555 .566 .57} Frequency, $\mathbf{G H z}$

Fig.5. Via diameter effect of slotted EBG structure (gap, $\mathrm{g}=2 \mathrm{~mm}$ ).

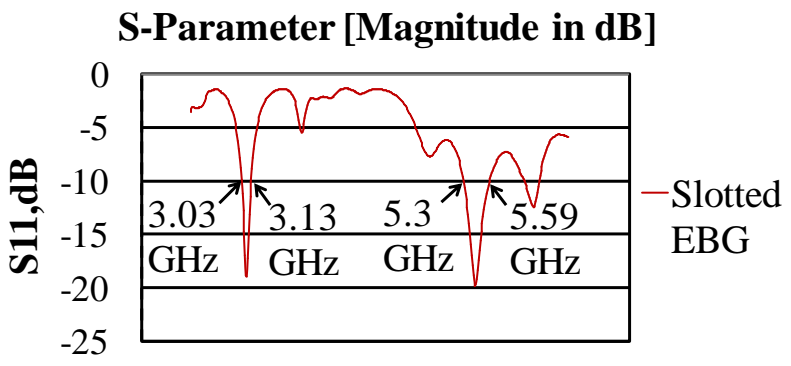

22.533 .544 .555 .566 .57

\section{Frequency,GHz}

Fig.6. Simulated result for the proposed antenna with slotted EBG structure, input reflection coefficient $\left(S_{11}\right)$.

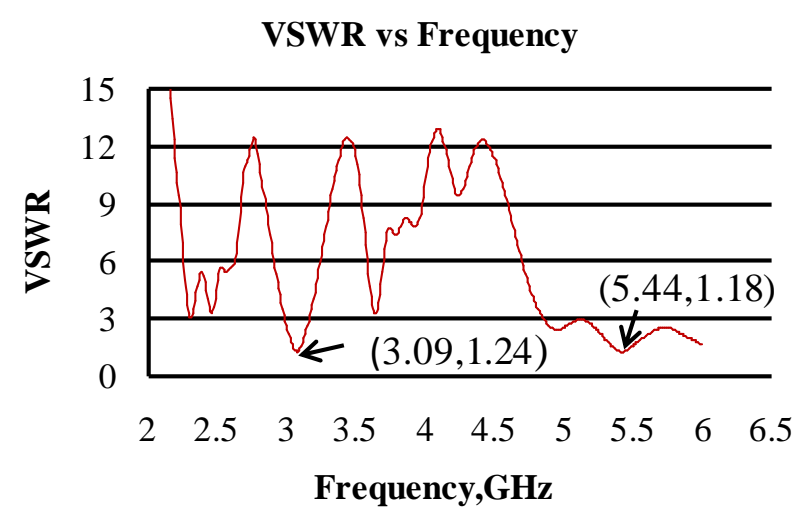

Fig.7.VSWR vs Frequency curve.

unit cells contributes to create capacitance effect. As the gap increases, the higher stop band shifts towards the higher side due to an increase in the capacitance value. For the maximum bandwidth and gain, the gap is optimized and found to be $\mathrm{g}=2 \mathrm{~mm}$. Fig. 4 shows the gap effect between EBG elements while Fig. 5 shows the via 
Gain vs Frequency

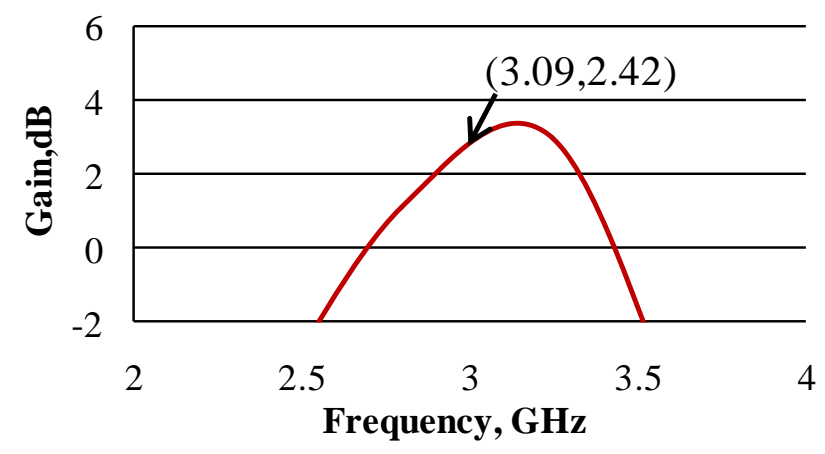

Fig.8. Simulated gain of the proposed antenna at $3.09 \mathrm{GHz}$.

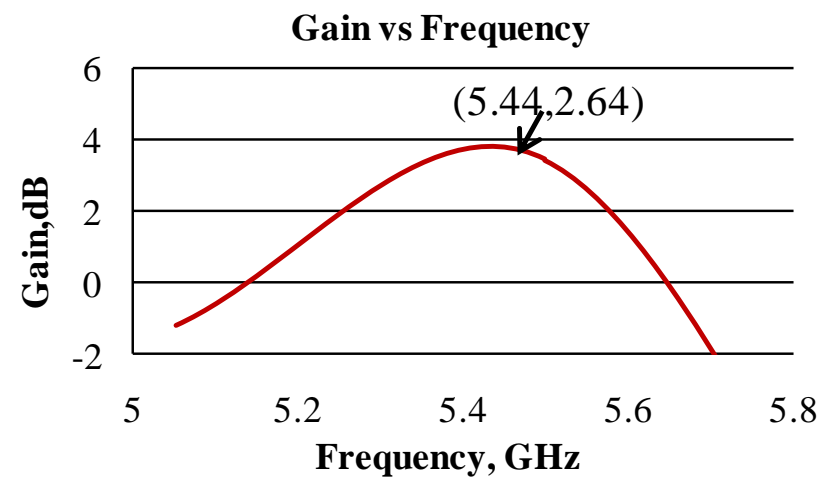

Fig.9. Simulated gain of the proposed antenna at $5.44 \mathrm{GHz}$.

\section{E-plane}

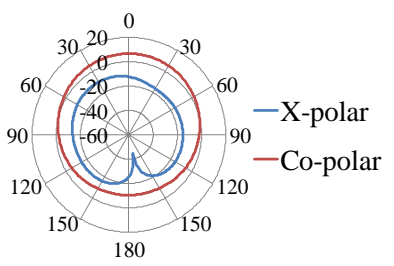

Theta/Degree vs. dB

Fig.10. Simulated radiation patterns of proposed antenna

(a) E-plane at $3 \mathrm{GHz}$ (b) $\mathrm{H}$-plane at $3.09 \mathrm{GHz}$.

\section{E-plane}

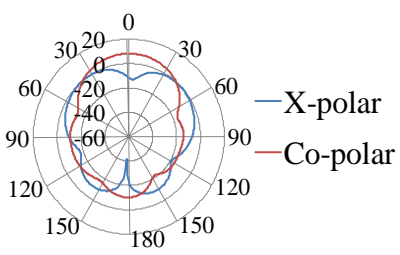

Theta/Degree vs. dB

(a)

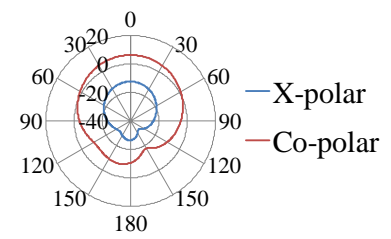

Theta/Degree vs. dB

\section{(b)}

\section{H-plane}

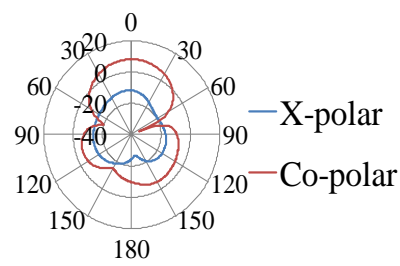

Theta/Degree vs. dB

(b)
Fig.11. Simulated radiation patterns of proposed antenna (a) E-plane at $5.44 \mathrm{GHz}$ (b) $\mathrm{H}$-plane at $5.44 \mathrm{GHz}$. diameter effect. If via diameter increases, the higher stop band shifts towards the higher frequency ranges

due to a decrease in the via inductance. For the maximum bandwidth and gain, the diameter is optimized and found to be $\mathrm{D}=0.8 \mathrm{~mm}$. There is no gap effect and via diameter effect in the lower stop band frequency. The simulated transmission parameter $\left(S_{11}\right)$ of our proposed microstrip patch antenna with slotted EBG structure for $\mathrm{g}=2 \mathrm{~mm}$

\section{S-Parameter [Magnitude in $\mathbf{~ d B}$ ]}

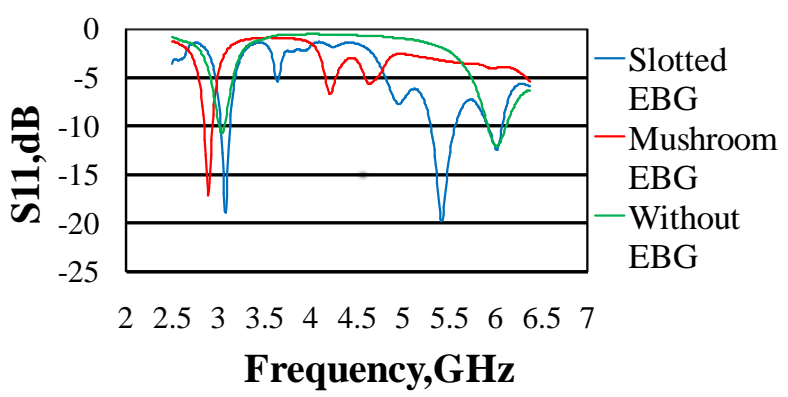

Fig.12.Comparative simulation Results $\left(S_{11}\right)$ of microstrip patch antenna with and without EBG.

Table IV. Performance Comparison of Simulated Results of the designed microstrip patch antenna with and without EBG

\begin{tabular}{ccccc}
\hline \hline $\begin{array}{c}\text { Antenna } \\
\text { Design }\end{array}$ & $\begin{array}{c}\boldsymbol{f}_{\boldsymbol{c}} \\
(\mathbf{G H z})\end{array}$ & $\begin{array}{c}\text { Return } \\
\text { Loss } \\
(\mathbf{d B})\end{array}$ & $\begin{array}{c}\text { BW } \\
(\boldsymbol{\%})\end{array}$ & $\begin{array}{c}\text { Gain } \\
(\mathbf{d B})\end{array}$ \\
\hline $\begin{array}{c}\text { Without } \\
\text { EBG }\end{array}$ & 3.03 & -10.53 & 1.65 & 2.5 \\
$\begin{array}{c}\text { With } \\
\text { Mushroom }\end{array}$ & & & & \\
$\quad$ EBG & 2.92 & -15.18 & 2.73 & 2.7 \\
$\begin{array}{c}\text { MEBG) } \\
\text { With }\end{array}$ & & & & \\
$\begin{array}{c}\text { Slotted } \\
\text { EBG }\end{array}$ & 3.09 & -19.16 & 3.24 & 2.42 \\
(SEBG) & 5.44 & -21.35 & 5.33 & 2.64 \\
\hline \hline
\end{tabular}

Table V. Performance Comparison Table

\begin{tabular}{llllll}
\hline \hline Ref. & $\begin{array}{c}\boldsymbol{f}_{\boldsymbol{c}_{\mathbf{1}}} / \boldsymbol{f}_{\boldsymbol{c}_{\mathbf{2}}} \\
(\mathbf{G H z})\end{array}$ & $\operatorname{Size}\left(\mathbf{m m}^{\mathbf{2}}\right)$ & $\begin{array}{l}\text { BW } \\
(\boldsymbol{\%})\end{array}$ & $\begin{array}{l}\text { Gain } \\
(\mathbf{d B})\end{array}$ & VSWR \\
\hline$[6]$ & 1.56 & $60 \times 52$ & 6.4 & -- & -- \\
& 3.17 & & 1.89 & -- & -- \\
{$[\mathbf{1 9}]$} & 2.4 & $56 \times 56$ & 2.5 & -- & -- \\
& & & & & \\
{$[\mathbf{2 0}]$} & 2.6 & $80 \times 110$ & 5.7 & 4.2 & -- \\
& 5.7 & & 4.3 & 1.76 & \\
{$[\mathbf{2 1}]$} & 1.65 & $100 \times 90$ & 2.4 & -- & 1.35 \\
& 3.32 & & 2.5 & -- & 1.09 \\
& & & & & \\
This & 3.09 & $47 \times 47$ & 3.24 & 2.42 & 1.24 \\
work & 5.44 & & 5.33 & 2.64 & 1.18 \\
& & & & & \\
\hline \hline
\end{tabular}

and $\mathrm{D}=0.8 \mathrm{~mm}$ is shown in Fig.6. The operating bandwidth of the antenna is $100 \mathrm{MHz}$ (3.03-3.13) GHz at $3 \mathrm{GHz}$ and $290 \mathrm{MHz}(5.3-5.59) \mathrm{GHz}$ at $5.44 \mathrm{GHz}$. The calculated fraction bandwidth (FBW) is $3.24 \%$ at $3.09 \mathrm{GHz}$ and $5.33 \%$ at $5.44 \mathrm{GHz}$, which can be calculated as (8).

$$
F B W=\frac{f_{\text {max }}-f_{\text {min }}}{f_{c}} \times 100=\frac{B W}{f_{C}}
$$

Where, $f_{c}$ is the resonance frequency of the antenna. The FBW of our proposed antenna with slotted EBG structures is improved by 1.25 times compared to mushroom type EBG and 2 times compared to without 
EBG structure at 3.09GHz. VSWR (Voltage Standing wave Ratio) curve is shown in Fig.7. As VSWR value of this proposed antenna are 1.24 at $3.09 \mathrm{GHz}$ and 1.18 at $5.44 \mathrm{GHz}$, so we can see that the calculated value is less than 2 throughout the operating band, which makes the antenna suitable for microwave application. The gain of the antenna is shown in Fig.8. and Fig.9. The introduction of the slots in EBG unit cell generates dual band and improves the antenna bandwidth. The simulated radiation patterns at $3.09 \mathrm{GHz}$ and at $5.44 \mathrm{GHz}$ are shown in Fig.10. and Fig. 11.

To examine the performance characteristics of our proposed EBG structure, a comparison between slotted EBG structure and square mushroom-like EBG structure is analyzed. Fig.12. shows the comparison results of the parameter of $S_{11}$ of microstrip patch antenna design with mushroom-like EBG, with slotted EBG and without EBG structure. As we can see, with mushroom-like EBG structure the patch radiates only at around $3 \mathrm{GHz}$. After incorporating rectangular and U-shaped slots in each EBG cell, there is a second frequency band at around 5.44GHz. The comparison between mushroom EBG and slotted EBG structure shows that the proposed slotted EBG structure has a wider bandwidth at lower frequency. Our proposed microstrip patch antenna with slotted EBG structure is compared with mushroom-like EBG structure and without EBG structure in Table IV. in terms of its return loss, BW and gain.

Our proposed antenna is compared with the other recently published work in Table V. in terms of its size, BW, gain and VSWR. The comparison shows that the proposed antenna achieves a better gain and wider bandwidth than the other state-of-arts.

\section{CONCLUSION}

A dual band microstrip patch antenna operating in the $S$ band and C-band is presented. This antenna resonates at around $3.03-3.13 \mathrm{GHz}$ and $5.3-5.59 \mathrm{GHz}$. Simulated results show an impedance bandwidth of $100 \mathrm{MHz}$, a gain of $2.42 \mathrm{~dB}$, a VSWR of 1.24 at $3.09 \mathrm{GHz}$ and an impedance bandwidth of $290 \mathrm{MHz}$, a gain of $2.64 \mathrm{~dB}$, a VSWR of 1.18 at $5.44 \mathrm{GHz}$. The proposed antenna is working from 3.03 to $3.13 \mathrm{GHz}$ which is applicable for weather radar, surface ship radar, some communications satellites and working from 5.3 to $5.59 \mathrm{GHz}$ which is applicable for satellite communications transmissions, Wi-Fi devices, weather radar systems, wireless applications, surveillance.

\section{REFERENCE}

[1] O. Ayop, M. K. A. Rahim, and T. Masri, "A dual band gap slotted patch electromagnetic band gap for dual band microstrip antenna," in proc. of IEEE Int. RF Microw. Conf. RFM , pp. 322-325, 2008.

[2] P. Rezaei, "EBG structures properties and their application to improve radiation of a low profile," Journal of Information Systems and Telecommunication, vol. 1, no. 4, pp. 251-259, 2013.

[3] B. Ramesh and V. Rajya Lakshmi, "Design Of A Rectangular Microstrip Antenna Using EBG Structure," Int. J. Eng. Res. Technol., vol. 2, no.
7, pp. 2233-2236, 2013.

[4] M. S. Alam, M. T. Islam, N. Misran, and D. E. Selangor, "Design Analysis of An Electromagnetic Band Gap Microstrip Antenna," Am. J. Appl. Sci., vol. 8, no. 12, pp. 1374-1377, 2011.

[5] P. P. Bhavarthe, S. S. Rathod, and K. T. V. Reddy, "A Compact Dual Band Gap Electromagnetic Band Gap Structure," IEEE Trans. Antennas Propag., vol. 67, no. 1, pp. 596-600, 2019.

[6] M. Bai, W. Ren, Z. Xue, and W. Li, "The design of EBG for enhancing the isolation in dual-band microstrip antennas," in proc. of 2019 Photonics Electromagn. Res. Symp. - Fall, PIERS - Fall 2019 - Proc., pp. 2207-2212, 2019.

[7] X. Zhang, Z. Teng, Z. Liu, and B. Li, "A dual band patch antenna with a pinwheel-shaped slots EBG substrate," Int. J. Antennas Propag., vol.15, 2015.

[8] M. K. Abdulhameed, M. S. M. Isa, Z. Zakaria, M. K. Mohsin, and M. L. Attiah, "Mushroom-like EBG to improve patch antenna performance for C-band satellite application," Int. J. Electr. Comput. Eng., vol. 8, no. 5, pp. 3875-3881, 2018.

[9] A. Kumar, J. Mohan, and H. Gupta, "Surface wave suppression of microstrip antenna using different EBG designs," in proc. of Int. Conf. Signal Process. Commun., pp. 355-359, 2015.

[10] Zaid, Jamal, Mohammadmahdi Farahani, and Tayeb A. Denidni, "Miniatunrized microstrip patch antenna using electromagnetic bandgap (EBG) for GPS applications," IEEE International Symposium on Antenna Technology and Applied Electromagnetics (ANTEM), pp. 1-2, 2016.

[11] K. Srivastava and R. Kumar, "Study of u-slot electromagnetic band GAP structure and its effect on hexagonal patch antenna," in proc. of Int. Conf. Adv. Comput. Commun. Technol. ACCT, no. 3, pp. 138-143, 2013.

[12] H. Kim and R. F. Drayton, "A Novel dual-band Compact Electromagnetic Bandgap ( EBG ) Structure and its Application in MultiAntennas,"IEEE Antennas and Propag. Society Int. Symposium, pp. 1943-1946, 2006.

[13] Hamid, Muhammad Abdul, Mohamad Kamal A. Rahim, and Umar Mussa. "Dual band electromagnetic band gap structure with wideband antenna." IEEE International Symposium on Antennas and Propagation (ISAP), pp. 960-961, 2016.

[14] A. Kumar, D. Arya, and D. K. Srivastava, "Band width of microstrip antenna improved by using mushroom type EBG structure," IMPACT Proc. Int. Conf. Multimed. Signal Process. Commun. Technol., pp. 159-162, 2013.

[15] Qu, Dan, and L. Shafai, "The performance of microstrip patch antennas over high impedance EBG substrates within and outside its bandgap."in proc. of IEEE International Symposium on Microwave, Antenna, Propagation and EMC Technologies for Wireless Communications, vol. 1, pp. 423-426, 2005.

[16] B. W. Ngobese and P. Kumar, "A high gain 
microstrip patch array for $5 \mathrm{GHz}$ WLAN applications," Adv. Electromagn., vol. 7, no. 3, pp. 93-98, 2018.

[17] F. Yang and Y. Rahmat-Samii, "Microstrip Antennas Integrated with Electromagnetic BandGap (EBG) Structures: A Low Mutual Coupling Design for Array Applications," IEEE Trans. Antennas Propag., vol. 51, no. 10 II, pp. 29362946, 2003.

[18] H. R. Cheng, Q. Y. Song, Y. C. Guo, X. Q. Chen, and X. W. Shi, "Design of a novel ebg structure and its application in fractal microstrip antenna," Prog. Electromagn. Res. C, vol. 11, pp. 81-90, 2009.

[19] Singh, Jaget, B. S. Sohi, and Kanav Badhan. "Slit loaded H-Shaped Microstrip Patch Antenna for 2.4 GHz." International Journal of Applied Engineering Research, vol. 13, no. 18 pp. 1355213554,2018.

[20] Tu, D. T. Thanh, N. V. Hoc, and V. V. Yem, "Double-Side Electromagnetic Band Gap Structure for Improving Dual-Band MIMO Antenna Performance." REV Journal on Electronics and Communications, vol. 7, no. 1-2, 2017.

[21] Singh, Indrasen, V. S. Tripathi, and S. Tiwari, "Dual-band microstrip patch antenna miniaturization using metamaterial." Journal of Engineering,vol.13, 2013. 